\title{
Secretion of atrial natriuretic peptide from the heart in man
}

\author{
DONALD R J SINGER, JOHN W DEAN, * MARTIN G BUCKLEY, \\ GIUSEPPE A SAGNELLA, GRAHAM A MACGREGOR \\ From the Blood Pressure Unit, Department of Medicine, and ${ }^{\star}$ Department of Physiology, Charing Cross and \\ Westminster Medical School, London
}

SUMMARY Plasma concentrations of atrial natriuretic peptide were measured in eight patients undergoing elective cardiac catheterisation and angiography. All patients had normal resting pressures in the cardiac chambers and no clinical evidence of heart failure. Plasma atrial natriuretic peptide rose significantly from the superior vena cava into the right atrium and right ventricle. The increase into the right atrium was variable, with no increase in three subjects, but there was a consistent increase in all subjects from the superior vena cava to the right ventricle. These findings in the right atrium are probably caused by inadequate mixing and streaming of blood from the coronary sinus containing high concentrations of atrial natriuretic peptide. There was no increase in the concentration of natriuretic peptide from the pulmonary artery to the left ventricle, but the concentrations in the left ventricle were significantly higher than in the superior vena cava.

These findings demonstrate that the heart secretes atrial natriuretic peptides in the absence of cardiac failure. Studies based on sampling of the right atrium will not accurately measure cardiac secretion of atrial natriuretic peptide and will therefore be likely to obscure the mechanisms responsible for regulating its secretion. The right ventricle and pulmonary artery are the best sampling sites to measure atrial natriuretic peptide release from the right atrium.

There is increasing evidence that atrial natriuretic peptide may be important in the regulation of salt and water balance. ${ }^{1}$ The mechanisms controlling the release of atrial natriuretic peptide are not yet clear. Both in subjects with normal ${ }^{2}$ and with raised right atrial pressure, ${ }^{23}$ plasma concentrations of atrial natriuretic peptide in the right atrium have been reported to correlate significantly with right atrial pressure. However, the plasma concentration of atrial natriuretic peptide in coronary sinus blood is many times higher than that in peripheral venous and right atrial blood. ${ }^{4-7}$ Samples of right atrial blood are therefore likely to be of incompletely mixed venous blood. Richards $e t \mathrm{al}^{5}$ and Sato $e t \mathrm{al}^{6}$ confined their analysis of the mechanisms determining release of atrial natriuretic peptide to study-

Requests for reprints to Dr Graham A MacGregor, Blood Pressure Unit, Department of Medicine, Charing Cross and Westminster Medical School, London W6 8RF.

Accepted for publication 9 March 1987 ing relations with concentrations of atrial natriuretic peptide in the pulmonary artery and they did not consider changes in plasma concentrations of atrial natriuretic peptide at different cardiac sites within the same individual.

We measured plasma concentrations of atrial natriuretic peptide in blood samples taken from a neripheral vein, the superior vena cava, and in the chambers of the heart during routine cardiac catheterisation and coronary angiography in patients who had possible ischaemic heart disease but normal cardiac pressures.

\section{Patients and methods}

The eight white patients (five men and three women; mean age 60.5 years, range 54-67) studied were undergoing elective cardiac catheterisation as part of routine assessment of known or suspected cardiac disease (ischaemic heart disease seven; aortic stenosis one). Six were on drug treatment ( $\beta$ adrenergic blockers, calcium entry antagonists, nitrates). No 
patient had overt cardiac failure, and all had normal renal and liver function.

Cardiac catheterisation was performed via the right brachial artery under local anaesthesia with $1^{\circ}{ }_{0}$ lignocaine. A size 7 French multipurpose catheter (521-776 Cordis Corporation, Miami, USA) was inserted and used to measure pressure and to take blood samples from a peripheral vein, the superior vena cava, right atrium, right ventricle, and pulmonary artery. Patients were given 5000 IU heparin without bacteriocide immediately after the insertion of the arterial catheter (size 8 French National Institute of Health catheter 512-845, Cordis Corporation) that was used to measure arterial and left ventricular pressures and obtain blood samples. We recorded pressures with a semiconductor transducer (Medex Incorporated, Ohio, USA) and fibreoptic system (VR-12, E for M/Honeywell, New York, USA), taking the mid-axillary line as the zero reference point. All recordings and samples were taken with the patients supine before the administration of radiographic dye.

Blood for the measurement of atrial natriuretic peptide was taken into potassium ethylene diamine tetra-acetic acid and trasylol (aprotinin, Bayer, $2000 \mathrm{kIU} / 10 \mathrm{ml}$ blood) and spun immediately at $4^{\circ} \mathrm{C}$. Separated plasma was stored at $-20^{\circ} \mathrm{C}$. After Sep-pak extraction we measured immunoreactive atrial natriuretic peptide by radioimmunoassay. ${ }^{8}$ Plasma renin activity ${ }^{9}$ and aldosterone ${ }^{10}$ were also measured by radioimmunoassay.

We used the Statistical Package for Social Sciences of the North Western Universities (on the University of London computer) for statistical analysis by paired $t$ test, the binomial test, and Pearson and Spearman's correlation. Results are given as mean $(\mathrm{SE})$.

\section{Results}

PLASMA CONCENTRATIONS OF ATRIAL

NATRIURETIC PEPTIDE

Plasma concentrations of atrial natriuretic peptide in the right atrium $(45.2(8.6) \mathrm{pg} / \mathrm{ml})$, in the right ventricle $(43.8(7.7) \mathrm{pg} / \mathrm{ml})$ and in the pulmonary artery $(43.1(6.8) \mathrm{pg} / \mathrm{ml})$ were significantly higher than the concentration in the superior vena cava (32.0 $(5 \cdot 4) \mathrm{pg} / \mathrm{ml}$ ) (fig 1). Examination of individual changes from the superior vena cava into the right heart showed that in three of the eight subjects there was no change into the right atrium (fig 2a), whereas concentrations of atrial natriuretic peptide rose from the superior vena cava to the right ventricle in all eight patients (fig 2b). Plasma concentrations of atrial natriuretic peptide in peripheral vein were not significantly different from those in the superior vena cava. Plasma concentrations of atrial natriuretic peptide in the left ventricle $(38.2(4.5) \mathrm{pg} / \mathrm{ml})$ were significantly greater than those in the superior vena cava $(p<0.05)$. In contrast with the increase in concentrations across the right side of the heart, concentrations in the left ventricle were not significantly different from those in the pulmonary artery (fig 1). Plasma concentrations of atrial natriuretic peptide were not significantly correlated with right atrial mean or pulmonary capillary wedge pressure. However, plasma concentrations of atrial natriuretic peptide in the right atrium $(r=0.81)$, right ventricle $(r=0.71)$, pulmonary artery $(r=0.77)$, and left ventricle $(r=0.82)$ correlated significantly with right ventricular systolic pressure $(p<0.05)$. The significance values quoted for the results are for parametric tests. The non-parametric tests gave similar values.

\section{CALCULATED RATE OF SECRETION OF ATRIAL NATRIURETIC PEPTIDE}

There was a mean increase in plasma concentrations of atrial natriuretic peptide of $11.7 \mathrm{pg} / \mathrm{ml}(95 \%$ confidence interval 5.9 to $17.5 \mathrm{pg} / \mathrm{ml}$ ), from superior vena cava to right ventricle. If the mean stroke volume is estimated to be $80 \mathrm{ml},{ }^{11}$ with a mean heart rate of 60 beats/min during the procedures, then the calculated mean secretion rate for atrial natriuretic peptide across the right atrium in these subjects was approximately $940 \mathrm{pg} / \mathrm{s}$. This assumes adequate mixing of blood by the time it reaches the right ventricle and no appreciable metabolism of atrial

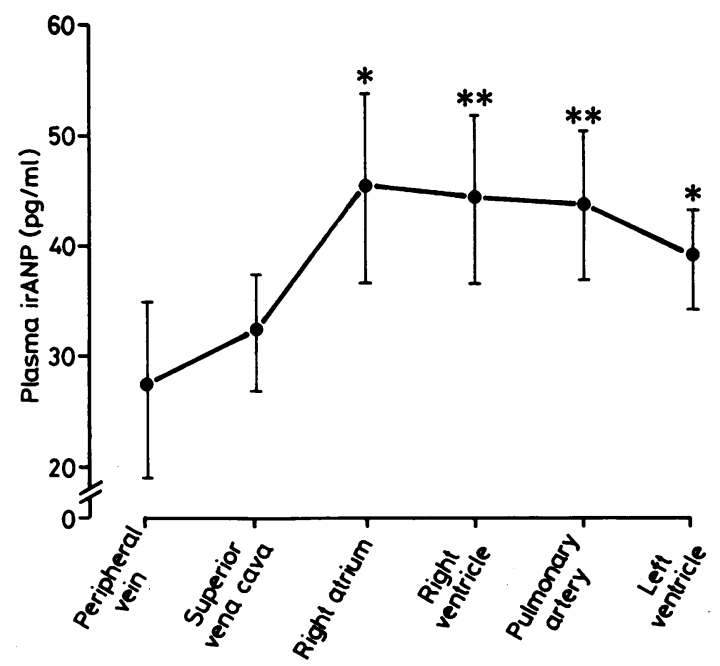

Fig 1 Plasma concentrations of atrial natriuretic peptide in samples from a peripheral vein $(n=6)$, superior vena cava $(n=8)$, and heart $(n=8)\left({ }^{\star} p<0.05 ;{ }^{\star}{ }_{p}<0.01\right.$ compared with samples from the superior vena cava). 

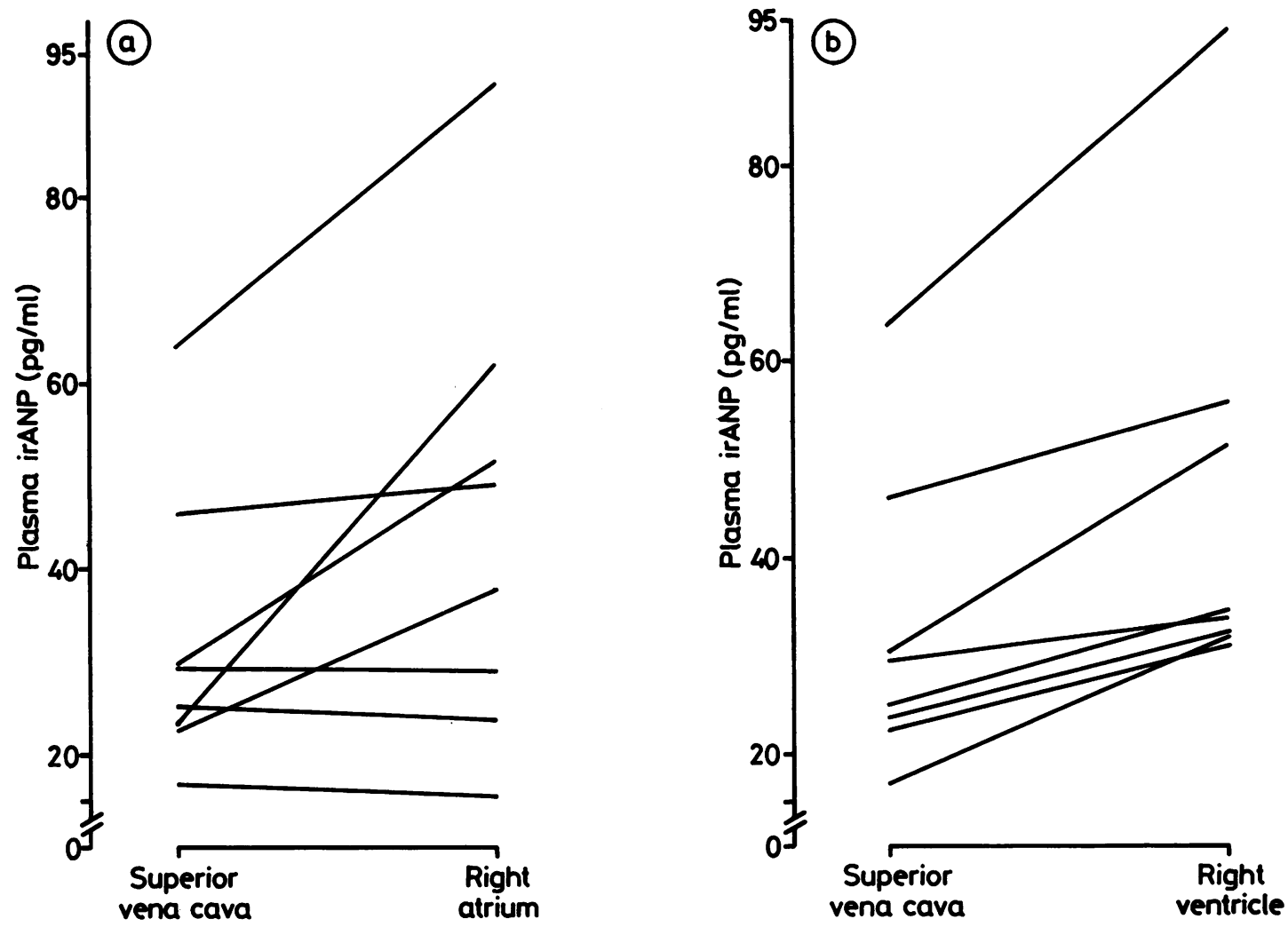

Fig 2 (a) Plasma concentrations of atrial natriuretic peptide in samples from the superior vena cava and right atrium. (b) Plasma concentrations of atrial natriuretic peptide in samples from the superior vena cava and right ventricle. ir ANP, immunoreactive atrial natriuretic peptide.

mixing of blood by the time it reaches the right ventricle and no appreciable metabolism of atrial natriuretic peptide during blood transit between these sampling sites. However, the mean net cardiac secretion of atrial natriuretic peptide calculated from the difference in mean plasma concentrations between the superior vena cava and the left ventricle $(6.1 \mathrm{pg} / \mathrm{ml}(95 \%$ confidence interval 1.1 to $11 \cdot 1 \mathrm{pg} / \mathrm{ml}$ ) was less, approximately $500 \mathrm{pg} / \mathrm{s}$.

Table 1 Cardiac catheter pressures in eight patients

\begin{tabular}{lr}
\hline Site & Pressure $($ SE) $\mathbf{m m ~ H g}$ \\
\hline R atrial mean & $1 \cdot 5(1 \cdot 1)$ \\
R ventricle systolic & $25 \cdot 0(1 \cdot 8)$ \\
R ventricle diastolic & $1 \cdot 2(0 \cdot 8)$ \\
Pulmonary artery systolic & $22 \cdot 0(0 \cdot 8)$ \\
Pulmonary artery diastolic & $7 \cdot 1(1 \cdot 0)$ \\
Pulmonary artery mean & $11 \cdot 1(1 \cdot 1)$ \\
Pulmonary capillary wedge & $4 \cdot 5(0 \cdot 9)$ \\
L ventricle systolic & $130 \cdot 0(7 \cdot 9)$ \\
L ventricle diastolic & $5 \cdot 6(1 \cdot 2)$ \\
L ventricle end diastolic & $4 \cdot 2(0 \cdot 6)$ \\
Aorta, systolic & $120 \cdot 6(6 \cdot 5)$ \\
Aorta, diastolic & $66 \cdot 2(4 \cdot 1)$ \\
\hline
\end{tabular}

\section{CARDIAC PRESSURES}

All subjects had normal right atrial mean pressure (range -2 to $6 \mathrm{~mm} \mathrm{Hg}$ ) as well as pulmonary capillary wedge pressure (range 2 to $10 \mathrm{~mm} \mathrm{Hg}$ ) (table 1) and none was hypertensive.

\section{OTHER MEASUREMENTS}

All subjects had normal renal and liver function. Plasma renin activity and aldosterone concentrations were within the normal range (table 2).

Table 2 Analysis of blood from the superior vena cava

\begin{tabular}{lc}
\hline & Mean $(S E)$ \\
\hline Plasma: & \\
Sodium $(\mathrm{mmol} / \mathrm{l})$ & $136 \cdot 5(2 \cdot 5)$ \\
Potassium $(\mathrm{mmol} / \mathrm{l})$ & $3 \cdot 7(0 \cdot 1)$ \\
Urea $(\mathrm{mmol} / \mathrm{l})$ & $5 \cdot 9(0 \cdot 6)$ \\
Creatinine $(\mu \mathrm{mol} / \mathrm{l})$ & $91 \cdot 4(10 \cdot 2)$ \\
Calcium $(\mathrm{mmol} / \mathrm{l})$ & $2 \cdot 32(0.09)$ \\
Albumin $(\mathrm{g} / \mathrm{l})$ & $41 \cdot 6(1.0)$ \\
Haemoglobin $(\mathrm{g} / \mathrm{dl})$ & $13 \cdot 6(0 \cdot 5)$ \\
Packed cell volume $\left({ }^{\circ} \mathrm{o}\right)$ & $0 \cdot 40(0 \cdot 02)$ \\
Plasma renin activity $(\mathrm{ng} / \mathrm{ml} / \mathrm{h})$ & $1 \cdot 26(0 \cdot 65)$ \\
Aldosterone $(\mathrm{pmol} / \mathrm{l})$ & $363 \cdot 2(91 \cdot 1)$ \\
\hline
\end{tabular}


Angiography showed normal coronary artery appearances in one patient, coronary artery disease in six, and both coronary artery disease and aortic stenosis in one patient.

\section{Discussion}

Our study shows that the concentration of plasma atrial natriuretic peptide increases from the superior vena cava into the right atrium and right ventricle and clearly demonstrates that the heart secretes atrial natriuretic peptide when cardiac pressures are normal. Sugawara et al studied four subjects and found a 3-10 fold increase in the concentration of atrial natriuretic peptide in the coronary sinus compared with that in peripheral venous blood. ${ }^{4}$ However, the majority of samples were assayed without extraction. This is now known to give erroneously high results because of interference from other substances in the plasma. ${ }^{7}$ When cardiac samples from one individual were measured after an extraction procedure no change was found in the plasma concentration of atrial natriuretic peptide from the inferior vena cava to the right atrium or the right ventricle and cardiac pressures were not reported. Direct assay in this individual gave values that were several fold greater than with the extraction procedure. $^{4}$

More recent studies have used an extraction step with either a radioimmunoassay ${ }^{356}$ or a radioreceptor assay ${ }^{212}$ to study plasma concentrations of atrial natriuretic peptide in subjects undergoing cardiac catheterisation. These have included patients with cardiac failure 25612 and with normal right atrial pressures. ${ }^{25612}$ Three of these studies examined correlations between concentrations of atrial natriuretic peptide in the right atrium and other factors. $^{2312}$ The other two studies considered the relation between concentrations of atrial natriuretic peptide in the pulmonary artery and cardiac haemodynamic function as well as biochemical measurements. But none of the above studies have examined the changes in plasma concentrations of atrial natriuretic peptide from the periphery across the chambers of the heart within the same individual.

In our study, we considered in detail the changes in plasma concentrations of atrial natriuretic peptide in individual subjects with normal cardiac chamber pressures. We found three of the eight subjects had no increase in plasma atrial natriuretic peptide in the right atrium compared with the superior vena cava, but they did have an increase in the right ventricle. In a further three subjects the rise from the superior vena cava to the right atrium was greater than the rise from the superior vena cava to the right ven- tricle. The wide variability in changes in concentrations of atrial natriuretic peptide from the superior vena cava to the right atrium in the eight subjects is likely to be due to a combination of the effects of the large contribution of the coronary sinus to atrial natriuretic peptide secretion ${ }^{4-6}$ streaming of blood in the right atrium, ${ }^{13}$ and within patient variation in the positioning of the sampling catheter in the atrium. The rise in the concentration of atrial natriuretic peptide from the superior vena cava to the right ventricle and the pulmonary artery was very similar in all subjects; mixing of blood containing low concentrations of atrial natriuretic peptide with that containing high concentrations is more likely to have occurred by the time atrial blood has reached these sites. Therefore, studies based on sampling the right atrium ${ }^{2312}$ are unlikely to be appropriate for determining the mechanisms of secretion. They may suggest spurious correlations and obscure important factors that determine the release of atrial natriuretic peptide.

Studies of the release of atrial natriuretic peptide from the heart should include sampling of the right ventricle or pulmonary artery or both because this will give a more accurate reflection of atrial secretion than direct right atrial sampling. Although Richards $e t a l^{5}$ and Sato $e t a l^{6}$ used this approach they gave no evidence to support their contention that the pulmonary artery is the more appropriate sampling site.

There are several possible explanations for the lack of increase in plasma atrial natriuretic peptide from the pulmonary artery to the left ventricle that we found in this study. It may be that the left atrium does not secrete atrial natriuretic peptide. This is unlikely, because, although the concentration of atrial natriuretic peptide in the left atrial muscle is lower, the net amount of atrial natriaretic peptide in the left atrium is similar to that in the right because the mass of the left atrium is greater than that of the right. Inactivation of atrial natriuretic peptide in the pulmonary circulation may possibly be important in man; however, animal studies have failed to show that metabolism of the lungs makes an appreciable contribution to the metabolism of atrial natriuretic peptide. ${ }^{14} \mathrm{~A}$ more likely explanation is that the left atrium secretes atrial natriuretic peptide into the left atrial veins which drain into the coronary sinus and then into the right atrium. The study by Ogawa et al supports the idea that release of atrial natriuretic peptide by the left atrium may, at least in cardiac failure, contribute significantly to circulating concentrations because they found a significant correlation between plasma concentrations of atrial natriuretic peptide in a peripheral vein and pulmonary capillary wedge pressure. ${ }^{15}$ In our study, in which patients did not have heart failure, at least as 
judged by the absence of clinical features and by normal resting cardiac pressures, there was no significant correlation between plasma concentrations of atrial natriuretic peptide in the heart and right atrial pressure. However, the right ventricular systolic pressure did correlate significantly with concentrations of atrial natriuretic peptide within all cardiac chambers sampled. The relevance of these findings is not clear and the numbers in our study were too small to allow definite conclusions to be drawn from such correlations.

Calculation of the secretion rate of atrial natriuretic peptide is based on several assumptions, but our study shows it should be possible to calculate approximate secretion of atrial natriuretic peptide across the heart, particularly when cardiac output is measured simultaneously. Our findings indicate that previous reports in which mechanisms for the secretion of atrial natriuretic peptide by the heart were postulated from correlations between haemodynamic and physicochemical variables and concentrations of atrial natriuretic peptide measured in the right atrium should be re-evaluated and the findings confirmed by sampling at sites at which mixing of blood is adequate.

DRJS is a British Heart Foundation Junior Research Fellow. GA MacG is a Wellcome Senior Lecturer.

\section{References}

1 Needleman P, Adams SP, Cole BR, et al. Atriopeptins as cardiac hormones. Hypertension 1985;7:469-82.

2 Raine AEG, Erne P, Burgisser E, et al. Atrial natriuretic peptide and atrial pressure in patients with congestive heart failure. $N \mathrm{Engl} J \mathrm{Med}$ 1986;315:533-7.

3 Hartter E, Weissel M, Stummvoll HK, et al. Atrial natriuretic peptide concentrations in blood from the right atrium in patient with severe right heart failure. Lancet 1985;ii:93-4.

4 Sugawara A, Nakao K, Morii N, et al. Alpha-human atrial natriuretic polypeptide is released from the heart and circulates. Biochem Biophys Res Commun 1985;129:439-46.

5 Richards AM, Cleland JGF, Tonolo G, et al. Plasma $\alpha$ natriuretic peptide in cardiac impairment. $\mathrm{Br} \mathrm{Med} J$ 1986;293:409-12.

6 Sato F, Kamoi K, Wakiya Y, et al. Relationships between plasma atrial natriuretic peptide levels and atrial pressure in man. J Clin Endocrinol Metab 1986;63:823-7.

7 Gutkowska J, Bonan R, Roy D, et al. Atrial natriuretic factor in human plasma. Biochem Biophys Res Commun 1986;139:287-95.

8 Sagnella GA, Markandu ND, Shore AC, MacGregor GA. Effects of changes in dietary salt intake and saline infusion on immunoreactive atrial natriuretic peptide in human plasma. Lancet 1985;ii:1208-11.

9 Roulston JE, MacGregor GA. Measurement of plasma renin activity by radioimmunoassay after prolonged cold storage. Clin Chim Acta 1978;88:45-8.

10 James VHT, Wilson GA. Determination of aldosterone in biological fluids. In: Reid E, ed. Assay of drugs and other trace compounds in biological fluids. (Methodological developments in biochemistry.) Amsterdam: Elsevier, 1976: vol. 5: S149-58.

11 Bevegard S, Holmgren A, Jonsson B. The effect of body position on the circulation at rest and during exercise, with special reference to the influence on the stroke volume. Acta Physiol Scand 1960;49: 279-98.

12 Burgisser E, Raine AEG; Erne P, Kamber B, Buhler FR. Human cardiac plasma concentrations of atrial natriuretic peptide quantified by radioreceptor assay. Biochem Biophys Res Commun 1985;133:1201-9.

$13 \mathrm{McDonald}$ DA. Blood flow in arteries. 2nd ed. London: Edward Arnold, 1974:87-8.

14 Weselcouch EO, Humphrey WR, Aiken JW. Effect of pulmonary and renal circulations on activity of atrial natriuretic factor. Am J Physiol 1985;249:R595-602.

15 Ogawa $\mathrm{K}$, Ito $\mathrm{T}$, Hashimoto $\mathrm{H}$, et al. Plasma atrial natriuretic factor in congestive cardiac failure [Letter]. Lancet 1986;i:106. 